\title{
MATERIAL QUALITY AT THE BORDER OF ECONOMIC AND TECHNOLOGICAL THINKING OF COMPANIES IN CHOSEN FIELDS AND BRANCHES OF METALLURGICAL PRODUCTION
}

\author{
Tomáš NĚMEC, Václav NÉTEK, Jaromír DRÁPALA \\ VSB - Technical University of Ostrava, Ostrava, Czech Republic, EU \\ tomas.nemec.st1@vsb.cz
}

https://doi.org/10.37904/metal.2019.975

\begin{abstract}
The article deals with the issue of the interconnection of economic and technological thinking in the process of selected product group and branches of metallurgical production. Growth in the commercial potential of distribution and redistribution of metallurgical products at large distances between the place of production and the place of consumption entails increased requirements for control of materials entering the manufacturing industry and final assembly. The research proved partial differences in the deviations of the declared values and the poor interpretation of the documents, accompanying selected deliveries. The pressure to save costs and reduce production processes in the middle of technology chains creates an interface between economic efficiency and technological security. The authors document this trend in selected examples.
\end{abstract}

Keywords: Economic thinking, technological thinking, material quality, rentability

\section{INTRODUCTION}

The growth of distribution and redistribution business potential of metallurgical secondary products at great distances between the place of production and the place of consumption brings with it increased demands on quality controls of the materials used for production in subsequent processing branches and in the final assembly. The conducted research showed differences in deviation of the declared values and a faulty interpretation of documents, which accompany the chosen supplies. Pressure on saving costs and streamlining production processes of companies at the middle of technological chains creates a border line between economic effectivity and technological safety.

\section{MATERIAL SAFETY ON THE INPUT SIDE OF THE CZECH REPUBLIC AND EU}

I The significantly increasing dependency of Czech republic and countries of the EU on import of primary raw ferrous and non-ferrous materials entails a few critical factors, which demand a far greater collaboration of available independent laboratory and diagnostic facilities (universities and research centers in the field of material engineering) and a chosen range of industrial companies, which purchase material, parts and components from manufacturers located from outside the EU. [4] The conducted research on selected materials and samples and products showed these key trends, which are on the border between being characterized as low quality products, and as such that threaten the material safety in many fields of technology chains. It is foremost the following critical problematic areas [1,2]:

- checking compliance with technological is focused on only the outcome document (attestations and others)

- business supplier chains, which oversee the voyage across thousands of kilometers between the manufacturer and the first customer don't have the necessary laboratory equipment for performing necessary quality controls due to saving costs

- $\quad$ the results, which should protect the end customer, especially in the USE stage of the final product manifest in the stage of CONSUMPTION or longtime wear. 
Do we know how to buy? Or do we only purchase the documents, attestations and emails.

Example results of findings in the diagnostic area of material safety:

- $\quad$ Surgery room ....orthopaedics .... products from titanium wire

- Telecommunication ....powder metallurgy ....supplies of metals with a high level of purity with biological additives [1,2]

- The car industry .... steel fasteners ....fatigue of threaded fasteners

- $\quad$ And the list goes on ....up to the production of optical devices.

Parts and components in terms of supply aren't such an economically significant stage on the input side to cause a need for any laboratory controls

What then is the current steel production situation like in the world?

One of the key elements for representing the whole development trend of the rate of evaluation of the available raw material sources and semi-manufactured products in terms of a set territorial and economic framework is decided by the worldwide supply of available raw material sources. Although, there are new production fields and technologies being encouraged, the sector of metallurgy on a worldwide scale is a continuously growing field. The world-wide production of steel reached 1692 million tons per year. This value is spread across individual territories in great disproportion in direct relation to their own size and consumption rate of the subsequent branches. Asian countries today produce 1162 mil.t, which represents $68,7 \%$ of world production from which China produces 821 mil.t, and Europe produces 313 mil.t from which EU produces 168 mil.t, which is $10 \%$ of the world's production. In the Table 1 is world production of raw steel in the 2017. [3]

Table 1 The map of the world production of raw steel [3]

\begin{tabular}{|l|c|c|}
\hline Region & $\mathbf{2 0 1 7}$ & share (\%) \\
\hline Asian & 1162 & 68.7 \\
\hline of which China & 821 & 49.7 \\
\hline of which Japan & 104 & 6,2 \\
\hline Europe & 319 & 18.5 \\
\hline North America & 116 & 6.9 \\
\hline Middle East & 34.9 & 2.7 \\
\hline Africa & 16 & 0.9 \\
\hline Australia/New Zealand & 6 & 0.4 \\
\hline World & 1692 & 100 \\
\hline
\end{tabular}

The Czech republic produces, according to EUROFER statistics, The European Steel Association, 4.6 mil.t, which represents $2.8 \%$ of the entire production of the EU, which represents approximately $0.3 \%$ of the world production. The production of stainless steel within EU countries is only 7.3 mil.t, and represents only $4 \%$ out of the entire volume of production. [3]

The share of wire rod production as a perspective and rapidly growing raw form is similar in Czech republic to the entire EU, and represents approximately $13 \%$ of the entire production of steel. If we were to mention export, then the entire trend stays at a constant level from year 2009, where the EU exports approximately 1.8 mil.t of this raw material. An entirely different case is import, where in comparison with the year 2009, import of wire rod reached 5.5 mil.t in year 2017, which is a $196 \%$ increase. 
The above-mentioned values, sourced from the annual report from Eurofer ,European Steel in Figures 2018', are only some of the indicating values, which prove an increasing raw material dependency and an insufficiency of subsequent processing fields in the EU. The situation is even more acute, if we consider that this is only wire rod. An increasing highly dynamic trend is the raw material form in the area of drawn wire and especially semi-finished products and parts from wire.

What are the main consequences of these trends:

Finding 01

By disconnecting the technology chain at the border between rolled and drawn wire and the technological side of its finalization, there is a limited possibility of application of the newest discoveries of science and research in the area of material engineering.

Finding 02

By disconnection the technology chain between the drawn wire and its finalization, there is a limited possibility to integrate ideas during the design of new construction solutions, which are dependent on catalogue selections of range of products of wire from world manufacturers.

Finding 03

In terms of European manufacturers in areas of metallurgical secondary production there isn't sufficient economic motivation for the maximum evaluation of available sources of rolled material, as the primary raw material of the EU, which is exported futher, as a raw material from outside the EU with a low amount of added value.

\section{AN EXAMPLE OF RESULTS OF MATERIAL DIAGNOSTICS ON THE INPUT SIDE OF THE COMPANY OF THE MATERIAL NITI}

Investigated on a metallographic sample of the drill bit WP30B. The sample of drill bit consisted of a cylindrical shank and a drill bit in the form of a helix with a tip. There were four samples taken from the WP30B drill bit by cutting on a fine saw with water cooling:

from the cylindrical part (Shank????) - longitudinal (labelled DL) and lateral sample (labelled DP) from the drill tip - longitudinal (labelled HL) and lateral sample (labelled HP)

The following tests were performed:

A. Metallography of the sample in an etched and non-etched state

B. X-ray of the microstructural analysis (BSE, EDX)

a) Metallograph of the sample - diamond-polished state, un-etched

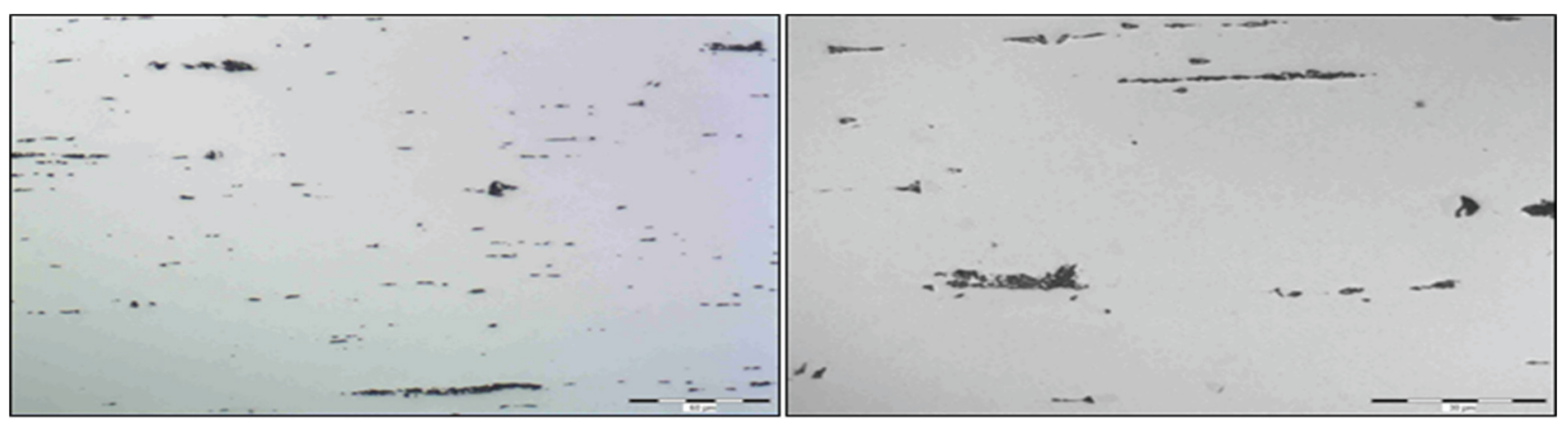

Figure 1 Microstructure of the NiTi endodontic tool (sample DL) - unetched [5] 


\section{ME'TAI 2019}

May $22^{\text {nd }}-24^{\text {th }} 2019$, Brno, Czech Republic, EU
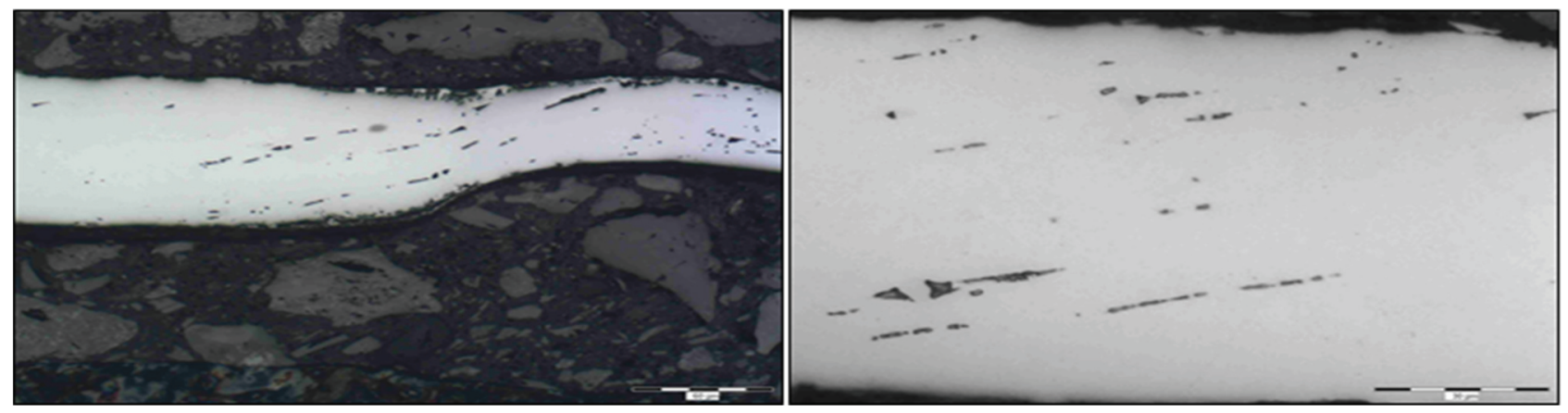

Figure 2 Metallograph of the drill (sample HL) - state unetched [5]

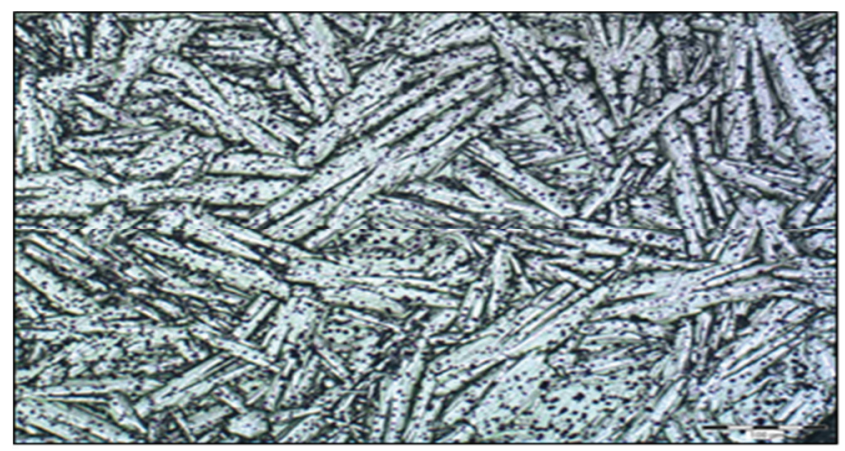

Figure 3 Metallograph of shank (sample DP)

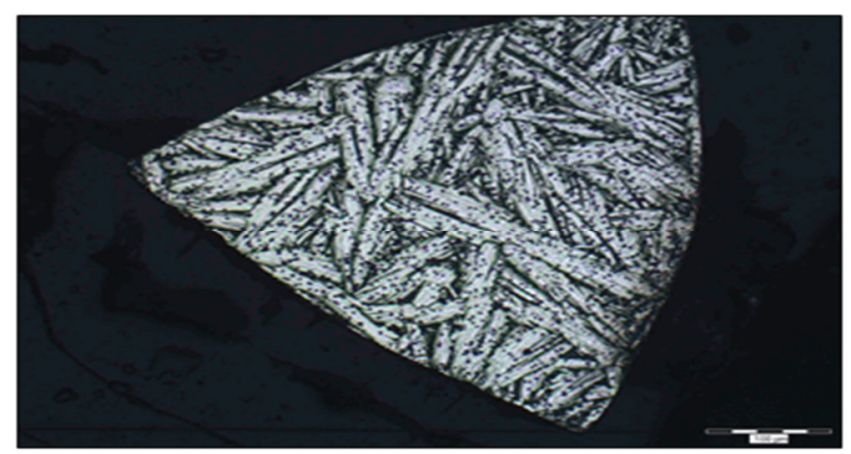

Figure 4 Metallograph of the drill in solution of acetic acid
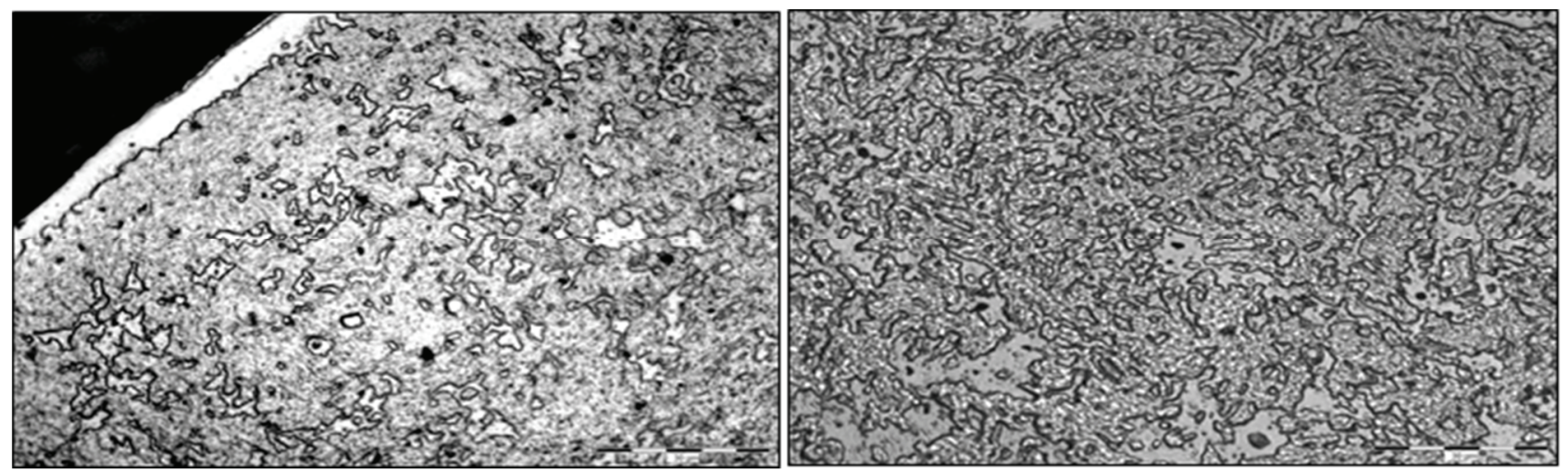

Figure 5 Metallograph of the shank (the edge of sample DP) (center of the sample) - etched in solution of $\mathrm{HNO}_{3}+\mathrm{Hcl}[5]$
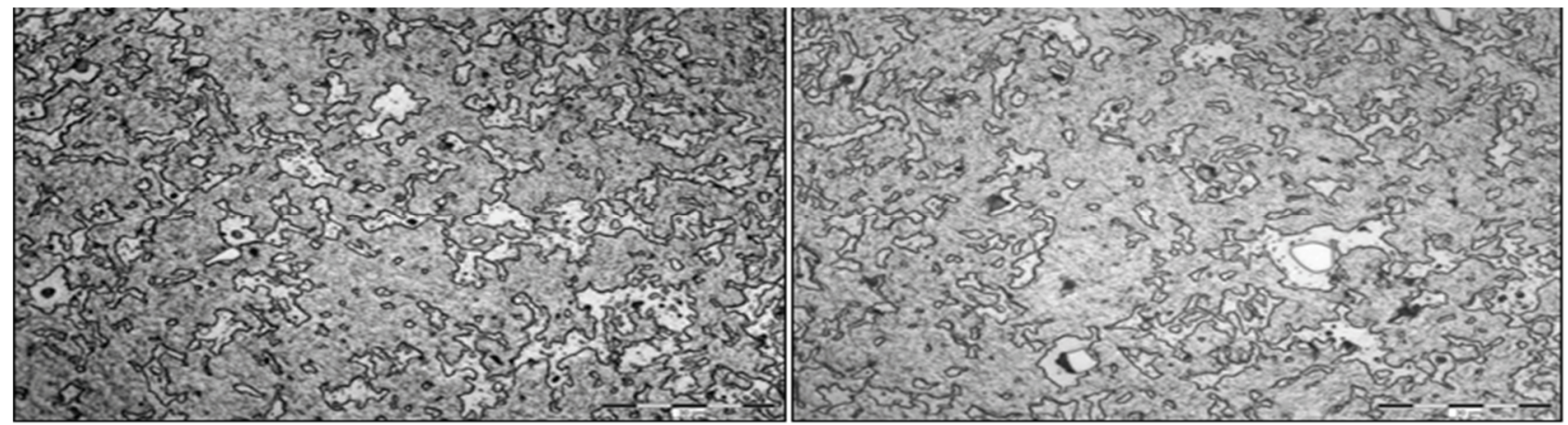

Figure 6 Metallograph of the shank (center of the sample) - etched in solution of $\mathrm{HNO}_{3}+\mathrm{Hcl}[5]$ 
Conclusions of the metallographic study of the sample WP30B:

In the unetched state there are evidently two stages in the structure, minor - probably $\mathrm{Ti}_{2} \mathrm{Ni}$ is stretched in the wire in the direction of the forging or the drawing - see Figure 1 and Figure 2. Etching in the aggresive solution of acids $\mathrm{HNO}_{3}+\mathrm{HF}$, it was possible to see the martensite structure in the lateral section of the sample - see Figure 4 and Figure 5. A solution of $\mathrm{HNO}_{3}+\mathrm{Hcl}$ was used for the etching of grain boundaries. The small black specks in the structure are evidence of the presence of titanium carbide.

b) X-ray microstructural analysis (BSE, EDX)

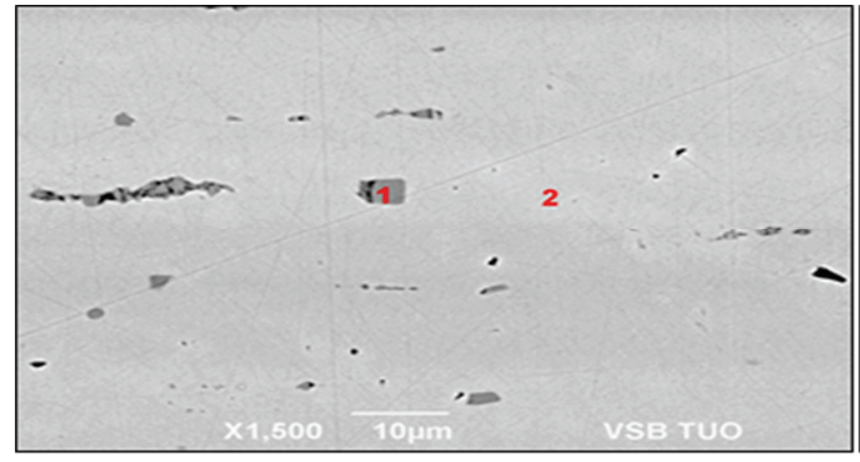

(longitudinal section)

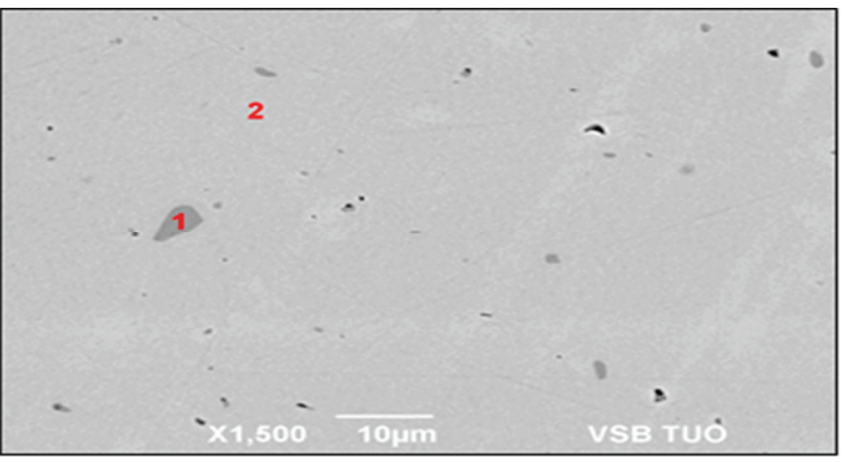

(lateral section)

Figure 7 BSE structural and phase microanalysis of shank (center of sample) [5]

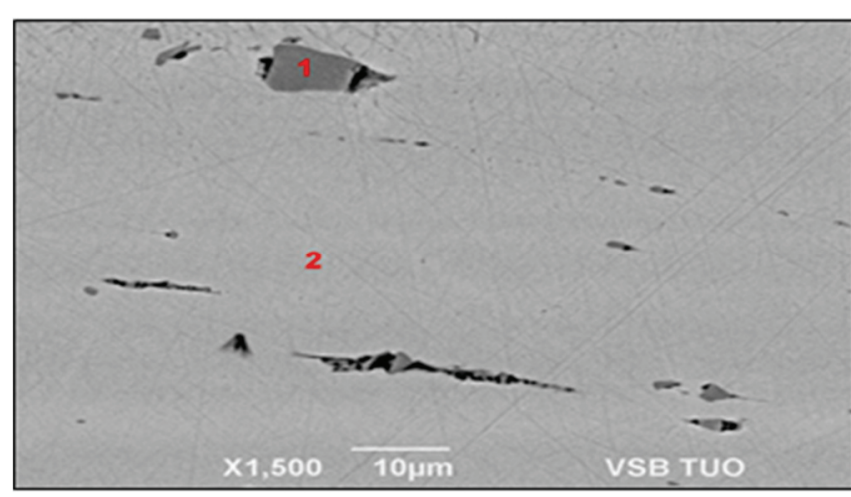

(longitudinal section)

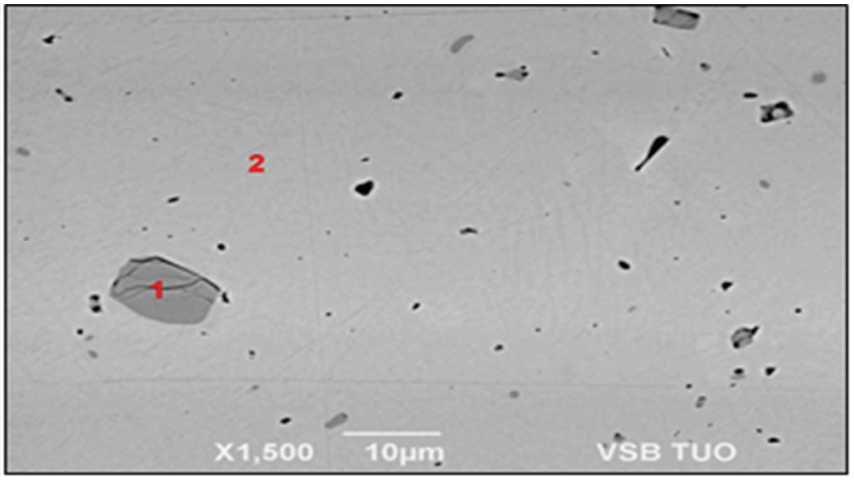

(lateral section)

Figure 8 BSE structural and phase microanalysis of the drill tip [5]

Table 2 X-ray EDX surface microanalysis and analysis of individual phases [5] weight $\%$

\begin{tabular}{|l|c|c|}
\hline Name & $\mathrm{Ti}$ & $\mathrm{Ni}$ \\
\hline plosna drik prodelny & 45.93 & 54.07 \\
\hline plosna drik pricny & 45.46 & 54.54 \\
\hline plosna hrot podelny & 45.52 & 54.48 \\
\hline plosna hrot pricny & 45.60 & 54.40 \\
\hline plo sna hrot pricny & 45.87 & 54.13 \\
\hline Spe ctrum1 drik podelny & 62.57 & 37.43 \\
\hline Spectrum1 drik pricny & 63.29 & 36.71 \\
\hline Spectrum1 hrot podelny & 62.42 & 37.58 \\
\hline Spectrum1 hrot pricny & 62.74 & 37.27 \\
\hline Spectrum1 hrot pricny & 59.37 & 40.64 \\
\hline Spectrum2 drik podelny & 45.63 & 54.37 \\
\hline Spectrum2 drik pricny & 45.41 & 54.60 \\
\hline Spectrum2 hrot podelny & 45.33 & 54.67 \\
\hline Spectrum2 hrot pricny & 45.69 & 54.31 \\
\hline
\end{tabular}

ato $\mathrm{mic} \%$

\begin{tabular}{|l|c|c|}
\hline Name & $\mathrm{Ti}$ & $\mathrm{Ni}$ \\
\hline plosna drik prodelny & 51.01 & 48.99 \\
\hline plosna drik pricny & 50.53 & 49.47 \\
\hline plosna hrot podelny & 50.60 & 49.40 \\
\hline plosna hrot pricny & 50.68 & 49.32 \\
\hline plosna hrot pricny & 50.95 & 49.05 \\
\hline Spectrum1 drik podelny & 67.20 & 32.80 \\
\hline Spectrum1 drik pricny & 67.88 & 32.12 \\
\hline Spectrum1 hrot podelny & 67.06 & 32.94 \\
\hline Spectrum1 hrot pricny & 67.36 & 32.64 \\
\hline Spectrum1 hrot pricny & 64.17 & 35.83 \\
\hline Spectrum2 drik podelny & 50.71 & 49.29 \\
\hline Spectrum2 drik pricny & 50.48 & 49.52 \\
\hline Spectrum2 hrot podelny & 50.41 & 49.60 \\
\hline Spectrum2 hrot pricny & 50.77 & 49.23 \\
\hline
\end{tabular}


EDX (BSE) analysis also proved the presence of three phases: matrix of $\mathrm{NiTi}$, $\mathrm{Ti}_{2} \mathrm{Ni}$ inclusions stretched in the direction of forging, which is a fragile phase in the intermetallic alloy and further there are carbides present (small dark forms) Table 2 shows the results of the chemical composition of the individual discovered phases. The presence of $\mathrm{Ti}_{2} \mathrm{Ni}$ is clearly proven here.

\section{THE SHOWING OF CRITICAL FUNCTIONS, AS A CONSEQUENCE OF DISCONNECITON OF TECHNOLOGY CHAINS}

In terms of the performed monitoring and technological research on the basis of the chosen range of fields of metallurgy products in the conditions of the Czech republic, there were a number of causal dependencies discovered, which lead to a need of increased material controls on the input side of the companies, associated with part and component production for finalizing manufacturers. It is namely the following findings:

- Disconnecting technology chains and technological operations due to the pressure on prices of the pressure on prices of the final global manufacturer

- Increasing the share of logistics costs in the total cost of production at the expense of critical technological cost and time needed for metallography and form transformation of the investigated material

- A change in technological communication, due to disconnection and atomisation of technological chains

- An insufficiency of a unified technological profession structure, due to the application of economic model of stream - lined production, engineering and outsourcing

- $\quad$ An increasing distance between place of production of the primary material and place of own processing and usage of technology of forming and heat processing of the final product pushes diagnostics of interoperational controls and especially experience into the area of table processors and virtual reality generators

These are only some of the findings of the area of cooperation and transformation of selected areas of metallurgical production in the conditions of Czech Republic, investigated since the year 2007. The matter of competitive ability and quality uniqueness of companies in places with low sources of own primary raw material sources, especially in the case of non-iron metal, demands an increased attention not only in the Czech republic but also in other companies of the European Union.

\section{CONCLUSION}

The issue of material quality on the input side of the companies requires increased attention everywhere, where there is a disconnection of unified technological processes. It is foremost the areas, which are associated with transport of material parts and components over large distances. In most investigated cases of metallurgy of secondary products, an issue arises by the mutual interaction of the amount of logistics and manipulation operations, and the effect of structures of often-times complicated business chains, which don't have a direct relationship with the primary manufacturer. Purchasing represents a significant gate for diagnostics in the future, and guarantees the future of qualitative elements of the subsequent technological process which leads to the finalization phase of the product, and foremost its use. The buying stage represents simultaneously one of the critical keys to a future uniqueness and to competitive ability.

\section{ACKNOWLEDGEMENTS}

The work was supported by the specific university research of the Ministry of Education, Youth and Sports of the Czech Republic in VSB - Technical University of Ostrava No. SP2019/62. 


\section{REFERENCES}

[1] KOTLER, P., KELLER, K. L. Marketing management, 14thEd., New Jersey: PearsonEducation, Inc., 2011.

[2] KOTLER, P., KELLER, K. L. Marketing management, 14.vyd., Praha: GradaPublishing, a.s., 2013.

[3] The European Steel Association. The European Steel Association [online]. 2018 [cit. 2019-03-05]. Available at: http://www.eurofer.org/Facts\%26Figures/Crude\%20Steel\%20Production/All\%20Qualities.fhtml

[4] NÉTEK, Václav. Technologie průmyslového marketingu. Ostrava: VŠB - TU Ostrava, 2018. ISBN 978-80-2484202-8.

[5] LOSERTOVÁ, M., ŠTENCEK, M., MATÝSEK, D., ŠTEFEK. O., DRÁPALA, J. Microstructure evolution of heat treated NiTi alloys. In 27th Joint Seminar Development of Materials Science in Research and Education. 4-8 September 2017, Kežmarské Žlaby, High Tatras, Slovakia. IOP Publishing. IOP Conf. Series: Materials Science and Engineering, 2017, vol. 266, 012008, 7 p. doi:10.1088/1757-899X/266/1/012008. 